\title{
Review on Psychological Test for Personnel Selection in Long Duration Mission to Extreme Environment
}

\author{
Dr. F. U. John Paul*
}

\begin{abstract}
:
This paper reviews literature related to the methods of personnel selection and the psychological assessment techniques for long duration missions in Antarctica and analogous environment. Drawing heavily from the current state of knowledge exemplified by various studies, this paper seeks to give an overview of some of the psychological factors pertinent to successful adaptation, and emphasizes the necessity of a standardized psychological assessment battery for use in selection of personnel for deployment to isolated and extreme environment..
\end{abstract}

Keywords: Antarctica, extreme environment, personnel selection, psychological screening

\section{INTRODUCTION}

It is harder to imagine the hostility of an extreme environment when human life is succumbed to the comforts of modern advancements of technological era. Nevertheless, isolated and extreme environments are still found on earth. People involved in long-duration voyages to high mountain peaks, desert islands, circumpolar regions, outer space mission, nuclear submarines, underwater laboratory and analogue environment are isolated and deployed in the most adverse environment that many consider to be hostile and unusual. Notwithstanding the risk of isolation and harsh environment, the conditions like remoteness, confinement, monotony, enforced togetherness impose several challenges for personnel in extreme environment. Therefore, the selection of personnel for deployment to such environment is a critical aspect for the success of accomplishing the missions, especially for long duration missions such as winter-over in Antarctica and long-duration spaceflight (Musson et al., 2004).

Considering the much interest these days on current fantasies about space travel and planetary exploration, the present study assumes greater significance, because it attempts to review literature dealing with selection procedures and psychological assessment techniques in personnel selection for long duration missions in Antarctica and analogous environment. Drawing heavily from the current state of knowledge exemplified by various studies, this paper seeks to give an overview of some of the psychological factors pertinent to successful adaptation, and emphasizes the necessity of a standardized psychological battery of tests for use in selection of personnel to isolated and extreme environment.

*Scientist 'C', DRDO, Air Force Selection Board, Mysore, Karnataka

(C) 2014 John Paul; licensee IJIP. This is an Open Access Research distributed under the terms of the Creative Commons Attribution License (http://creativecommons.org/licenses/by/2.0), which permits unrestricted use, distribution, and reproduction in any Medium, provided the original work is properly cited. 


\section{Methods of Personnel Selection in Antarctic and Space mission programmes}

In 1913, Shackleton, who is one of the first to be confronted with selection criteria, placed a newspaper ad that stated:

Men wanted for hazardous journey. Small wage, bitter cold, long months of complete darkness, ... Safe return doubtful.... and recognition in case of success. (Taylor, 1987, p. 17).

In the early days, the leader himself chose the members for the expedition, and the members were often the people whom the leader knew personally (Smith, 1961). On examining the selection criteria for successful Antarctic winter-over of British men, Paterson (1978) adjudged the ideal candidate as introverted, reserved, trusting, intelligent, self-sufficient, independent, and forthright.

Crocq, Rivolier, and Cazes (1974) described the elaborate selection procedures for French stations. Each applicant completes medical and biographic questionnaires, followed by an interview with a psychiatrist, and completes personality and intelligence tests, followed by an interview with a psychologist. This data is then matched with the subjects' performance in the Antarctic, including medical and emotional symptoms, station leader's report, physician's report, and efficiency, to validate the selection criteria (Rothblum, 1990)

Nowadays, most countries have adopted some form of psychological screening and selection to minimize the risk of poor psychosocial adaptation and decrements in task performance. The selection procedures include formal clinical psychological or psychiatric evaluations and psychological tests (Lugg, 2005), followed by the time-tested methods of personal interviews with mission administrators and former expeditioners. Psychiatric criteria are usually used for "selecting out" individuals who are not suitable for mission because of a personality or psychiatric disorder, or who may be at high risk for such disorders (Palinkas, Johnson, Boster, 2004). Psychological criteria are usually used for "selecting in" individuals with desirable characteristics, in an attempt to predict human adaptation and performance in these environments (Santy, 1994; Kanas \& Manzey, 2003).

Isolation and the life-threatening external environment are thought to be so stressful that only those with the "right stuff" could stand up to the challenge (Santy, 1994). Therefore, in the "selecting out" stage, candidates with inadequate preparation, overt psychopathology, and problematic life history are removed from further consideration. Interviews, biographical data, and tests (both objective and projective) are typically used. This screening has been emphasized because selectors view the environment as psychologically dangerous and "pathogenic" (Antonovsky, 1987).

The purpose of "selecting in" stage is to choose the best of the remaining candidates. Thus, the most challenging part of the selection process is "selecting in". To select in means identifying the applicants who are especially well suited for coping and for producing high performance in collaboration with others (Grant et al., 2007). Criteria regarding what constitutes desirability probably vary only slightly from environment to environment (Suedfeld \& Steel, 2000).

A number of countries have systematic programs for selecting personnel for longduration mission to outer space and polar expeditions. For example, Antarctica national 
programmes from USA, Canada, Chile, French, New Zealand, and Australia use psychological battery of selection, while the selection panel from UK chooses to do without it (Olson, 2002, Grant et al., 2007). The British Antarctic Survey (BAS) has no psychological evaluation in selection of personnel. Instead, selection is based on the professional judgment of experienced Antarctic staff who rely on operational criteria and interviews and a general medical examination. The latter includes only the most basic mental state assessment (Grant et al., 2007). The Russian space program uses a massive array of interviews and tests, with one stress test requiring a group of candidates to drive a small car cross country, which assesses group compatibility (Suedfeld \& Steel, 2000). The National Space Development Agency of Japan uses personality questionnaires, projective tests, encounter groups, participant observations, and interviews in attempting to select for positive social interaction characteristics (Santy, 1994). The winter-over Indian Antarctic expedition members undertake a battery of medical and psychological tests to qualify before the onset of expedition (John Paul et al., 2010). Unlike Antarctic national programmes, there is usually an explicit intellectual assessment in space programmes. Some psychological inventories such as NEOFFI (the "Big Five" personality inventory) and PCI (Personal Characteristics Inventory) are used in some of the Antarctic national programmes and space programmes (Steel et al., 1997; Musson et al., 2004). There is no validated psychological assessment tool for use in selection of personnel for service in Antarctica and analogous environment. It is also suggested that to include psychological inventory in the selection methods increases the chance of identifying good performers and reduces the chance of selecting poor performers (Musson et al., 2004; Grant et al., 2007).

\section{Psychological factors related to isolation and extreme environment}

Psychological adaptation to isolated, confined and extreme environment varies with factors such as personality traits, physiological characteristics, and the significant influence of environment on behavioural functioning. A number of researchers have investigated psychological factors related to the prolonged isolation and extreme envionrment. The most common symptoms associated with the austral winter in Antarctica are depression, irritability, aggressive behavior, insomnia, difficulty in concentration and memory, absentmindedness, and the occurrence of mild fugue states known as "long-eye" or the "Antarctic stare" (Palinkas et al., 1995; Palmai, 1963). For instance, during the 1989 winter season at McMurdo station, 62.1\% reported feeling depressed; $47.6 \%$ reported feeling more irritable than usual; and $51.5 \%$ reported difficulty with concentration and memory (Palinkas, 1992). Collectively, these symptoms are referred to as the "winter-over syndrome" (Strange \& Youngman, 1971).

During the long winter-over periods in Antarctica, personnel have reported increases in depressive mood, psychosomatic complaints, and interpersonal conflicts, and a decrement in work performance (Bhargava et al., 2000; Ikegawa et al., 1998; Palinkas and Johnson, 1990). Likewise, there are anecdotal and behavioural evidence from space missions that crewmembers have lapses of attention, emotional liability, psychosomatic symptoms, irritability toward others, and a considerable decline in vigor and motivation (Kanas and Manzey, 2003; Suedfeld, 2005). 
Nevertheless, other studies have found that isolation and confined environments are no more stressful than other environments (Suedfeld and Steel, 2000), and that high motivated and self-selected individuals who volunteer for such long-term missions are capable of maintaining high levels of performance over long periods of time (Palinkas et al., 2000)

Personnel who volunteer for long duration mission to Antarctica and Space mission programmes seem to possess common characteristics that differentiate them from people in general. Natani and Shurley (1974) found that individuals who adapt best to the Antarctic are those with good social skills who can also function in a monotonous, crowded environment without irritating their co-workers. Natani and Shurley (1974) labeled such individuals who adapt well to Antarctic living conditions as "professional isolates" (Rothblum, 1990). Succeeding the findings of several investigators, Palinkas (2003) stated that low expectations of the performance of fellow crew members and low need for social interaction are good characteristics of personnel living in isolated and confined environment.

Steel et al. (1997) observed that Antarctic expeditioners scored higher on measures of extraversion and openness to experience and lower on measures of neuroticism than population norms. In a prospective screening study of Antarctic winter-over personnel, the best performers were characterized by low levels of neuroticism (emotional liability), low desire for affection from others, low levels of boredom, low need for order, and a high tolerance for lack of achievement (Palinkas, et al., 2000). High achievement orientation and low stress reactivity have been found to be predominant characteristics in Antarctic scientists (Butcher and Ryan, 1974), and astronaut applicants at NASA (Musson et al., 2004).

On the basis of numerous reports of different expedition teams, a personality trait termed "absorption" has been identified (Atlis et al., 2004; Kahn and Leon, 1994; Leon et al., 1989). This characteristic refers to the ability to become highly engrossed in a particular activity to the exclusion of attending to other events that are happening around the person. For example, becoming so engrossed in the beauty of the Antarctic landscape that the monotony of the extensive physical exertion in a cold and windy environment is not processed as uncomfortable (Sandal, Leon, \& Palinkas, 2006). This unique characteristic of engagement in the beauty of the environment or becoming highly engrossed in a particular task would likely to result in successful adaptation for an extended period of time in isolated and extreme environment.

Among established personality approaches, the "Big Five" model (Costa \& McCrae, 1991) has considerable face validity for selection programs (Suedfeld \& Steel, 2000). High scorers on neuroticism which is related to Gunderson's "emotional stability" dimension are clearly a select-out criterion. Whereas, high scorers on conscientiousness, related to Gunderson's "task ability" and agreeableness (Gunderson's "sociability") would clearly be favourable signs for select-in criterion (Suedfeld \& Steel, 2000). The other two dimensions namely extraversion and openness to experience have mixed indicators (Suedfeld \& Steel, 2000).

\section{Standardization of psychological test for use in personnel selection}

As highlighted in previous section, the wide range of psychological factors associated with isolation and extreme condition has led the researchers to use a number of psychological 
inventories for evaluation of personnel in selection for deployment in isolated, confined and extreme environment. In most cases, the various psychological tests that are administered for screening an individual have no validation for use in selection of personnel to extreme environment such as space. In an attempt to validate a psychological test for use in selection of Antarctic personnel, Grant et al., (2007) developed the Selection of Antarctic Personnel (SOAP) battery which consisted of nine well-known psychological instruments. The aim of SOAP was to investigate whether standard psychological tests can predict how people actually will adapt to and cope with winter life in Antarctica. This study found no significant agreements between those actually selected by the British Antarctic Survey (BAS) panel and the selection one would have recommended based on the psychological test profiles of SOAP battery. As one of the reason for lack of significant agreement, it was stated that the interview boards based their selection on factors other than personality, social skills, and motivation, as these were not measured by the SAOP battery (Grant et al., 2007). Nevertheless, further research, in similar lines, is required for improvements in selecting out and selecting in personnel for isolated and extreme environment.

\section{CONCLUSION}

The criteria of selection process for deployment of personnel to isolated and extreme environment have been sharpened over the years so that incidences of severe psychological maladjustment and psychopathology are rare. Psychologists who are involved in selection or screening of personnel for service in isolated and extreme environment, such as Antarctica, have a large pool of potential volunteers who could manage the required technical work, yet who may have difficulty in coping with the extreme isolation and stressful living conditions. Therefore, the selection procedure must deal with important factors that are identified as unique or good characteristics of personnel living and working in isolated and extreme environment. The selection process, rather than selecting out psychopathological tendencies, should select in the desirable characteristics as suggested by several investigators. With respect to selection of personnel, there remains a need to develop a standardized psychological assessment battery for use in deployment of personnel in isolated and extreme environment. Also, research is required to develop a comprehensive psychological instrument with all personality and performance components that would optimize the select-in process.

\section{REFERENCES}

1. Antonovsky, A. (1987). Unraveling the Mystery of Health: How people manage stress and stay well. San Francisco: Jossey-Bass.

2. Atlis, M.M., Leon, G.R., Sandal, G.M., \& Infante, M. (2004). Decision processes and interactions during a two-woman traverse of Antarctica. Environment and Behavior, 36, 402-423.

3. Bhargava, R., Mukerji, S., \& Sachdeva, U. (2000). Psychological impact of the Antarctic winter on Indian expeditioners. Environment and Behavior, 32 (1), 111-27. 
4. Butcher, J.N., \& Ryan, M. (1974). Personality stability and adjustment to an extreme environment. Journal of Applied Psychology, 1, 25-44.

5. Costa, P.T. \& McCrae, R.R. (1991). Revised NEO Personality Inventory and NEO Five Factor Inventory. Lutz, FL: Psychological Assessment Resources, Inc.

6. Crocq, L., Rivolier, J., \& Cazes, G. (1974). Selection and psychological adjustment of individuals living in small isolated groups in French Antarctic stations. Antarctic Bibliography, 7, 228.

7. Grant, I., Eriksen, H.R., Marquis, P., Orre, I.J., Palinkas, L.A., Suedfeld, P., Svensen, E., \& Ursin, H. (2007). Psychological selection of Antarctic personnel: the "SOAP" instrument. Aviation, Space, and Environmental Medicine, 78, 793-800.

8. Ikegawa, M., Kimura, M., Makita, K., \& Itokawa, Y. (1998). Psychological studies of a Japanese winter-over group at Asuka Station, Antarctica. Aviation, Space, and Environmental Medicine, 69, 452-60.

9. John Paul, F.U., Mandal, M.K., Ramachandran, K., \& Panwar, M.R. (2010).Cognitive performance during long-term residence in a polar environment. Journal of Environmental Psychology, 30, 129-132.

10. Kahn, P.M., \& Leon, G.R. (1994). Group climate and individual functioning in an all women's Antarctic expedition team. Environment and Behavior, 26, 669-97.

11. Kanas, N., \& Manzey, D. (2003). Space psychology and psychiatry. Kluwer Academic Press, Dodrecht.

12. Leon, G.R., McNally, C., \& Ben-Porath, Y.S. (1989). Personality characteristics, mood, and coping patterns in a successful north pole expedition team. Journal of Research Personality, 23, 162-179.

13. Lugg, D.J. (2005). Behavioural health in Antarctica: implications for long-duration space missions. Aviation, Space, and Environmental Medicine, 76(Suppl), B74-B77.

14. Musson, D., Sandal, G.M., \& Helmreich, R.L. (2004). Personality characteristics and trait clusters in final stage astronaut selection. Aviation, Space, and Environmental Medicine, 75, 342-349.

15. Natani, K., \& Shurley, J.T. (1974). Sociopsychological aspects of a winter vigil at south polar station. In: Gunderson EKE, ed. Human adaptability to Antarctic conditions. Washington, DC: American Geophysical Union, 89-114.

16. Olson, J.J. (2002). Antarctica: A review of recent medical research. Trends in Pharmacological Sciences, 23(10), 487-490.

17. Palinkas, L.A \& Johnson, J.C. (1990). Social relations and individual performance of winter-over personnel at McMurdo Station. Antarctic Journal of the United States, 25, 238-240.

18. Palinkas, L.A. \& Browner, D. (1995). Effects of prolonged isolation on stress, coping, and depression. Journal of Applied Social Psychology, 25, 557-576.

19. Palinkas, L.A. (1992). Going to extremes: The cultural context of stress, illness and coping in Antarctica. Social Science and Medicine, 35, 651-664. 
20. Palinkas, L.A. (2003). The psychology of isolated and confined environments: understanding human behaviour in Antarctica. American Psychologist, 58, 353-363.

21. Palinkas, L.A., Gunderson, E.K., Holland, A.W., Miller, C., \& Johnson, J.C. (2000). Predictors of Behaviour and Performance in Extreme Environments: The Antarctic Space Analogous Program. Aviation, Space, and Environmental Medicine, 71(6), 619-25.

22. Palinkas, L.A., Johnson, J.C., \& Boster, J.S. (2004). Social support and depressed mood in isolated and confined environments. Acta Astronautica, 54, 639-47.

23. Palmai, G. (1963). Psychological observations in an isolated group in Antarctica. British Journal of Psychiatry, 109, 364-370.

24. Paterson, R.A.H. (1978). Personality profiles in a group of Antarctic men. International Review of Applied Psychology, 27, 33-37.

25. Rothblum, E.D. (1990). Psychological factors in the Antarctic. The Journal of Psychology, 124 (3), $253-273$.

26. Sandal, G.M., Leon, G.R., \& Palinkas, L.A. (2006). Human challenges in polar and space environments. Review of Environment Science Biotechnology, 5, 281-296.

27. Santy, P.A., (1994). Choosing the Right Stuff: The Psychological Selection of Astronauts and Cosmonauts. London: Praeger.

28. Smith, W.M. (1961). Scientific personnel in Antarctica: Their recruitment, selection and performance. Psychological Reports, 9, 163-182.

29. Steel, G.D., Suedfeld, P., Peri, A., \& Palinkas, L.A. (1997). People in high latitudes: the "Big Five" personality characteristics of the circumpolar sojourner. Environment and Behavior, 29, 324-47.

30. Strange, R.E., \& Youngman, S.A. (1971). Emotional aspects of wintering over. Antarctic Journal of the United States, 5, 255-257.

31. Suedfeld, P. (2005). Invulnerability, coping, salutogenesis, integration: four phases of space psychology. Aviation, Space, and Environmental Medicine, 76, B61-B66.

32. Suedfeld, P., \& Steel, G. (2000). The environmental psychology of capsule habitats. Annual Review of Psychology, 51, 227-253.

33. Taylor, A.J.W. (1987). Antarctic psychology. Wellington: Department of Scientific and Industrial Research. 